\author{
Asian Development Policy Review \\ $\operatorname{ISSN}(e): \quad 2313-8343$ \\ $\operatorname{ISSN}(p): \quad 2518-2544$ \\ DOI: 10.184.88/journal.107.2013.11.1.14 \\ Vol. 1, No. 1, 1-14 \\ (C) 2013 AESS Publications. All Rights Reserved. \\ URL: www.aessweb.com
}

\title{
MATERNAL HEALTH-CARE IN INDIA: THE CASE OF TETANUS TOXOID VACCINATION
}

\author{
Rana Ejaz Ali Khan ${ }^{1+}$ \\ Muhammad Ali Raza ${ }^{2}$
}

'Associate Professor, Department of Economics, the Islamia University of Bahawalpur, Bahawalpur Pakistan.

${ }^{2}$ M.Phil. student, Applied Economics Research Center University of Karachi, Karachi, Pakistan.

(+ Corresponding author)

\section{ABSTRACT}

Keywords

Woman health South Asia

Female education

Woman autonomy

Husband's education

Household wealth

Prenatal-care

Regional disparity.

\section{JEL Classification:} $\mathrm{I} 10, \mathrm{~J} 13$
Prenatal-care is one of the important elements of maternal healthcare. In this paper an attempt has been made to examine the socioeconomic determinants of Tetanus Toxoid (TT) vaccination as a component of prenatal-care by the women in the age group of 1549 years. Micro-data having 25847 observations from Indian Demographic and Health Survey (IDHS) has been used. To estimate the probability of TT vaccination binary logistic regression has been utilized. The explanatory variables categorized into sociodemographic characteristics of the woman, household characteristics, health-related characteristics, community characteristics and regional characteristics have been included in the analysis. The results explained that probability to have TT vaccination increases by woman' education, woman' age at marriage, husband's age, husband's education, husband's living within household, husband's presence at prenatal visit and household wealth. The woman's living in small city, town and country side as well as final say on woman's health-care by woman and husband collectively, and husband alone decrease the probability of TT vaccination. The study proposed targeted approach to enhance the TT vaccination in Indian women. The marginalized households should be targeted through cash transfer programs. Furthermore, the small cities and country sides should also be focused. The awareness and education of woman along with husband's participation in maternal health-care cannot be ignored in policy making.

\section{INTRODUCTION}

In the developing world, the social, behavioral and environmental context of a woman's health, the discussion merged on maternal health. Furthermore, a woman's health in these 
countries typically implies reproductive health as well as a woman's capacity to produce children. As a result, efforts primarily focus analytically and programmatically on indicators of maternal health. Maternal mortality, neonatal mortality and low birth-weight are major outcome indicators of maternal health. The input indicators include prenatal-care, postnatal-care and fertility control. In the prenatal-care, Tetanus Toxoid (TT) vaccination is one of the important components of maternal health in developing economies. The neonatal tetanus is a leading cause of infant mortality in many developing countries (Stanfield and Galazka, 1984; Whitman et al., 1992). A recent study estimated that neonatal tetanus contributes between zero and 21 percent of all neonatal deaths in India (Lahariya et al., 2010).

Similarly, Bassani et al. (2010) concluded that neonatal infection alone account for 250 to 270 thousand neonatal deaths in India ${ }^{1}$. On the other hand, maternal TT vaccination (TT vaccination in the coming pages) is the single most effective intervention against neonatal tetanus. It is independent of all other protective approaches, including aseptic care of the umbilical cord, inhospital deliveries and home deliveries attended by trained health workers (Gupta and Keyl, 1998). The immunization of pregnant women or women of childbearing age with two doses of TT vaccination may reduce the neonatal tetanus mortality by 94 percent (Blecowe et al., 2010). Singh et al. (2012) opined that two doses of TT vaccination can avert the 16 percent neonatal deaths in rural India (see also Gupta and Keyl (1998) for same type of effect).The United Nation's Children Fund (UNICEF), the World Health Organization (WHO) and United Nation's Population Fund (UNFPA) have established the goal of elimination of maternal neonatal tetanus deaths and established a global fund for its elimination. The elimination of maternal neonatal tetanus deaths means the achievement of less than one case per 1000 live births annually in every district of a country in the world.

The three key strategies for the purpose recommended by UNICEF/WHO and UNFPA are provision of at least two doses of TT vaccination to all pregnant women in high risk areas and three doses to all women of child bearing age, promotion of clean delivery services to all pregnant women and ensuring the effective surveillance for maternal neonatal tetanus. In most of the developing countries, TT vaccination program is implemented as part of the routine vaccination program as a supplemental activity. Despite the considerable resources being invested into the routine vaccination program in India since early 1970s, the TT vaccination among women remained low due to demographic, sociocultural and economic factor ${ }^{2}$.

In India75 percent pregnant women receive prenatal-care, the women receiving TT vaccination is 59 percent and 52 percent births are attended by skilled health staff ${ }^{3}$. It results into neonatal mortality rate of 32.2 per 10,000 live births and maternal mortality rate of 200 per

\footnotetext{
${ }^{1}$ India is one of the eight highest burden countries including Bangladesh, China, Congo, Ethiopia, Nigeria, Pakistan and Somalia.

2 Generally they range woman's age at marriage, woman's current age, woman's education, her working status, empowerment and decisionmaking, household's socioeconomic status, household size, rural-urban locality of the household, husband' education, employment and income, accessibility to health-care providers (Maral, et. al. 2001), caste and religion (Singh, et. al. 2012).

${ }^{3}$ A significant ratio of deliveries is attended by non-expert health workers in developing countries like India, which enhance the importance of implementation of TT vaccination in these economies.
} 
100,000 live births. In this background, we focus on India to see the determinants of TT vaccination. The core objective of the study is to analyze the socioeconomic determinants of TT vaccination and to frame policy proposals for the improvement in TT vaccination in India.

\section{REVIEW OF LITERATURE}

Maternal health is the problem peculiarly in developing economies. A number of studies have focused on maternal health in different perspectives. Currently we are concerned with TT vaccination, so the studies focused on TT vaccination exclusively are covered in this section. Roosihermiatei et al. (2000) have investigated the factors associated with maternal TT vaccination in rural Indonesia by using primary data comprising of information from 64 pregnant women in the age group of 17-30 years. Majority of the women in the survey were housewives having more than one child and educated up to high school level. In the sample socioeconomic status of the household was low and major occupation was agriculture and traditional fishing. The study is a micro study and the results cannot be generalized. However, results have shown that women who had antenatal-care were 30 times more likely to have TT vaccination (irrespective of number of doses) as compared to those who did not. Similarly women having information about TT vaccination were 2.85 times more likely to receive TT vaccination as compared to their counterparts of having no information. The study proposed health education programs for enhancing the maternal health-care information.

Maral et al. (2001) have attempted to evaluate the TT vaccination status in Ankara (Turkey) and its determining factors using primary data of 493 observations from a hospital. Two multivariate logistic regression models were used to see the determinants of TT vaccination (at least one dose) and number of TT vaccination doses received by pregnant women. The study concluded that number of prenatal visits, rural-urban residence and type of prenatal-care facility, i.e. hospital/private practice or primary health service has significant effect on TT vaccination. The higher number of prenatal visits raises the likelihood of TT vaccination. Women who received prenatal-care from primary health service had a 12.67 fold higher chances of being vaccinated than those who received this care from hospital/private clinics. A surprising result emerged from the study was that rural women were more likely to have TT vaccination than their urban counterparts. The elucidation given was that doctors (mostly gynecologists) who practice in urban areas and particularly in private sector hospitals neglect to administer the TT vaccination assuming that the delivery will be held in hospital under ideal sterile condition $\mathrm{s}^{4}$. In the second model, the maternal age and number of prenatal-care visits surge the likelihood of two doses of TT vaccination. Primiparous women were 9.27 times more likely to receive two doses of TT than their multiparous counterparts. Thind (2005) estimated the determinants of TT vaccination of pregnant women in rural Bihar (India) and concluded that likelihood of pregnant

\footnotetext{
${ }_{4}^{4}$ The finding is very much significant for policy perspectives, as adaptation of this strategy may lead to escalate unprotected women, who would be open to tetanus infection for the rest of their lives and their babies during the first month of life prior to primary vaccination series. In every hospital every woman who visit for maternal health-care must be TT vaccinated and should be entered in vaccination history.
} 
women to have two doses of TT vaccination are affected by the factors like birth-order, maternal education, prenatal-care providers, living standard of the household, health-care seeking decisionmaking and service availability. Hasnain and Shaikh (2007) examined the factors of low TT vaccination in Lahore (Pakistan) using primary data of 362 observations. It is micro study like the Roosihermiatei et al. (2000), but such type of studies have the advantage of selection of particular variables which are generally lacking in national health surveys. However, the study concluded that poor knowledge, lack of decision-making power of women, low female literacy rate and poor attendance for prenatal-care were the factors of low TT vaccination.

The impact of TT vaccination on neonatal mortality in rural northern India(Rajasthan, Uttaranchal, Uttar Pradesh, Madihye Pradesh, Chattisgarh, Bihar and Jharkhand) has been probed by Singh et al. (2012) using Indian National Family Health Survey 2005-06. A discretetime logistic model was utilized to see the association between neonatal mortality and TT vaccination along with prenatal-care utilization and supplementation with iron and folic acid. The results explained that antenatal-care utilization and iron-folic acid supplementation has no significant effect on neonatal mortality while two doses of TT vaccination could stop the 78,632 neonatal deaths. There is an interesting result, that is supervised births had higher risk of neonatal mortality compared to the unsupervised births.

The explanation given is that in rural areas the risky births or deliveries with complications come to the supervised birth attendants like gynecologists and qualified medical professionals. The study further elaborated that mother's education, mother's age at birth of child, wealth status of household were significantly associated with provision of at least two doses of antenatal TT vaccination. Muslim mothers were 0.85 times more likely to avail TT vaccination as compared to Hindu mothers. In the current study we are going to use IDHS 2005-06 data for both urban and rural areas of India. It makes the current study deviating from that of Singh et al. (2012). So it will be an addition to the existing literature but with some new determinants.

\section{DATA SET AND METHODOLOGY}

\subsection{Data Set}

For estimating the determinants of TT vaccination, the micro-data has been taken from Indian Demographic and Health Survey 2005-06 (IDHS). The IDHS is a demographic, socioeconomic and health survey program devising data on family planning, reproductive health, maternal and child health, nutrition, immunization, education and employment.

\subsection{Measuring Maternal Health-care}

In the literature, maternal health-care is measured by the indicators like prenatal-care and postnatal-care and family planning practices. The prenatal-care utilization comprised of a variety of components. They are prenatal visits, timings of the first visit, utilization of the services at visits, supplement intakes in the form of vitamin A and iron and TT vaccination during pregnancy. To examine the determinants of TT vaccination, the variable (TT vaccination) is based on the answer to the question asked by IDHS, i.e. did you (respondent woman) have taken 
tetanus toxoid vaccination in the last pregnancy or not. The respondent has response either yes or no. The response for question is coded as 1 if the woman received tetanus toxoid vaccination otherwise zero. It forms the dependent variable (TT vaccination) as binary variable ${ }^{5}$.

\subsection{Selection of Explanatory Variables}

Gorossman (1972) first introduced the notion that demand for medical-care is derived from the demand for good health. The general determinants of medical-care in developing countries are: socio-demographic characteristics, disease-related characteristics, household characteristics, regional characteristics and community characteristics, etc. Andersen and Newman (1973) developed the behavioral model which has been widely used in analysis of health service disciplines like breast cancer screening (Birch et al., 2007), health-care for elderly persons (Jordan et al., 2006; Redondo-Sendino et al., 2006) as well as prenatal-care utilization (Beeckman et al., 2010; Titlay et al., 2010). The model gives the conceptual framework for determinants of healthcare.

The determinants of health-care (in the case of prenatal-care) may be external environment (region and type of residence), predisposing factors (socio-demographic: maternal age at delivery, household wealth index, occupational status, origin, maternal education, paternal education, maternal marital status, maternal final say on her own health-care, birth-order and interval; health knowledge: frequency of reading newspaper, frequency of listening to radio, frequency of watching television, knowledge of pregnancy complications, knowledge of delivery complications, knowledge of post-delivery complications), enabling factors (know where to go to seek health services, permission to visit health services, money to pay health services, distance to health services, transportation to health services, presence of companion, availability of care by female health workers, health insurance coverage, welfare benefits) and need factor ${ }^{6}$ (pregnancy complications, desire for pregnancy, parity, planned pregnancy, medically assisted pregnancy, high risk status during pregnancy).We have selected the explanatory variables partially covering the framework given by Andersen and Newman (1973).

\subsection{Model Specification}

Our model is concerned with TT vaccination having dependent variable as binary variable. So we have utilized the multivariate binary $\log$ it model. TT vaccination is affected by a set of explanatory variables. These variables are classified into three categories, so the general function of TT vaccination is given as:

\footnotetext{
${ }_{5}^{5}$ In the analysis we have included at least a single dose of TT vaccination (see also Maral, et. al. 2001 for Turkey). However, generally two doses are recommended during pregnancy and WHO, 1986. has recommended five doses of TT vaccination during reproductive age for long-term immunity. The single dose is questioned by the researchers regarding its effectiveness in protection (Stanfield, J.P., D. Gall and P.M. Brecken, 1973, Rahman, M., C. Chen, J. Chakraborty, M. Yunus, A.I. Chowdhury, A.M. Sarder, S. Bhatia and G.T. Curlin, 1982. whereas Black, R.E., D.H. Huber and G.T. Curlin, 1980. and Koeing, M.A., 1992. have evidenced the reduction of neonatal mortality due to single dose of TT vaccination.

${ }^{6}$ In the Andersen and Newman model the component is illness level that has been transformed in to need factor.
} 
TT vaccination $=\mathrm{f}$ (individual characteristics, household characteristics, regional characteristics)

For TT vaccination, the model is expressed as below:

$$
\begin{aligned}
& \text { TTV }=\mathrm{f}\left(\beta_{0}+\beta_{1} \text { WAGEM }+\beta_{2} \text { WEDU }+\beta_{3} \text { WWORK }+\beta_{4} \text { ETPREG }+\beta_{5} \text { BORD }+\beta_{6} \text { HAGE }+\right. \\
& \beta_{7} \text { HEDU }+\beta_{8} \text { HWORK }+\beta_{9} \text { HLHOME }+\beta_{10} \text { HPVISIT }+\beta_{11} \text { GENHH }+\beta_{12} \text { SAY }+\beta_{13} \text { FSTRUCT } \\
& \left.+\beta_{14} \text { HINSUR }+\beta_{15} \text { WIND }+\beta_{16} \text { RESIDE }\right) \ldots \ldots \ldots \ldots \ldots . . .
\end{aligned}
$$

\begin{tabular}{|c|c|}
\hline Variables & efinitions \\
\hline \multicolumn{2}{|l|}{ Dependent Variable } \\
\hline TTV (TT Vaccination) & $\begin{array}{l}\text { If the woman has received TT vaccination in the last } \\
\text { pregnancy }=1 \text {,otherwise }=0\end{array}$ \\
\hline \multicolumn{2}{|l|}{ Explanatory Variables } \\
\hline \multicolumn{2}{|l|}{ Individual Characteristics } \\
\hline $\begin{array}{l}\text { WAGEM (Woman's age at first } \\
\text { marriage) }\end{array}$ & Woman's age at first marriage in completed years \\
\hline WEDU (Woman's education) & $\begin{array}{l}\text { Illiterate }=0 \text {, Primary }=1 \text {, Secondary }=2 \text {, College and } \\
\text { higher }=3\end{array}$ \\
\hline WWORK (Woman's work status) & Working $=1$, otherwise $=0$ \\
\hline $\begin{array}{lll}\begin{array}{l}\text { ETPREG } \\
\text { pregnancy) }\end{array} & \text { (Ever } & \text { terminated } \\
\end{array}$ & Yes $=1$, No $=0$ \\
\hline BORD (Birth-order of the child) & Birth-order of the child of last pregnancy \\
\hline \multicolumn{2}{|l|}{ Household Characteristics } \\
\hline HAGE (Husband's age) & Husband's age in completed years \\
\hline HEDU (Husband's education) & $\begin{array}{l}\text { Illiterate }=0 \text {, Primary }=1 \text {, Secondary }=2 \text {, College and } \\
\text { higher }=3\end{array}$ \\
\hline HWORK (Husband's work status) & Working $=1$, otherwise $=0$ \\
\hline $\begin{array}{l}\text { HLHOME (Husband's living in } \\
\text { home) }\end{array}$ & Yes $=1$, No $=0$ \\
\hline $\begin{array}{l}\text { HPVISIT (Husband's presence } \\
\text { during prenatal visit) }\end{array}$ & Yes $=1$, No $=0$ \\
\hline $\begin{array}{l}\text { GENHH (Gender of head of } \\
\text { household) }\end{array}$ & Male $=1$, Female $=0$ \\
\hline $\begin{array}{l}\text { SAY (Final say on woman's } \\
\text { health-care) }\end{array}$ & $\begin{array}{l}\text { Someone else }=0, \text { Husband alone }=1 \text {, Woman and husband } \\
=2, \text { Woman alone }=3\end{array}$ \\
\hline FSTRUCT (Family structure) & Combined $=1$, Nuclear $=0$ \\
\hline $\begin{array}{l}\text { HINSUR (Household covered by } \\
\text { health insurance) }\end{array}$ & Yes $=1$, No $=0$ \\
\hline WIND (Wealth index) & $\begin{array}{l}\text { Poorest }=0 \text {, Poorer }=1, \text { Middle }=2, \text { Richer }=3 \text {, Richest }= \\
4\end{array}$ \\
\hline \multicolumn{2}{|l|}{ Regional Characteristics } \\
\hline RESIDE (Place of residence) & $\begin{array}{l}\text { Capital and large city }=0 \text {, Small city }=1 \text {, Town }=2 \text {, } \\
\text { Countryside }=3\end{array}$ \\
\hline
\end{tabular}

The operational definitions of the variables have been given in table-1.

Table-1. Operational Definitions of the Variables used in Binary Logit Model 


\section{RESULTS}

The results of binary logistic regression for TT vaccination of the woman are shown in table2. Majority of the results are consistent with conceptual implications of TT vaccination of the women.

Table-2. Result of Binary Logistic Regression for TT Vaccination of Women in India

\begin{tabular}{|c|c|c|c|}
\hline Variables & Coefficient & Std. Error & P-value \\
\hline \multicolumn{4}{|c|}{ Woman's age at first marriage [Continuous] } \\
\hline & .011 & .007 & $.093^{* *}$ \\
\hline \multicolumn{4}{|c|}{ Woman's education [No education as reference] } \\
\hline Primary & .130 & .060 & $.031 *$ \\
\hline Secondary & .126 & .057 & $.026^{*}$ \\
\hline Higher & .486 & .127 & $.000^{*}$ \\
\hline \multicolumn{4}{|c|}{ Woman's working status [No as reference] } \\
\hline Yes & -.057 & .043 & .183 \\
\hline \multicolumn{4}{|c|}{ Ever terminated pregnancy [No as reference] } \\
\hline Yes & .047 & .052 & .367 \\
\hline \multicolumn{4}{|c|}{ Birth-order of child [Continuous] } \\
\hline & -.165 & .014 & $.000^{*}$ \\
\hline \multicolumn{4}{|c|}{ Husband's age [Continuous] } \\
\hline & .017 & .004 & $.000^{*}$ \\
\hline \multicolumn{4}{|c|}{ Husband's education [No education as reference] } \\
\hline Primary & .138 & .063 & $.027^{*}$ \\
\hline Secondary & .216 & .056 & $.000^{*}$ \\
\hline Higher & .432 & .097 & $.000^{*}$ \\
\hline \multicolumn{4}{|c|}{ Husband's working status [No as reference $]$} \\
\hline Yes & .137 & .202 & .498 \\
\hline \multicolumn{4}{|c|}{ Husband living in home [No as reference $]$} \\
\hline Yes & .184 & .089 & $.038 *$ \\
\hline \multicolumn{4}{|c|}{ Husband's presence during prenatal visit [No as reference] } \\
\hline Yes & .304 & .041 & $.000^{*}$ \\
\hline \multicolumn{4}{|c|}{ Gender of head of household [Female as reference $]$} \\
\hline Male & -.091 & .075 & .223 \\
\hline \multicolumn{4}{|c|}{ Final say on woman's health-care [Someone else as reference] } \\
\hline Woman & -.092 & .091 & .312 \\
\hline Woman and husband & -.196 & .089 & $.027^{*}$ \\
\hline Husband alone & -.189 & .090 & $.035^{*}$ \\
\hline \multicolumn{4}{|c|}{ Family structure [Nuclear as reference] } \\
\hline Combined & -.037 & .043 & .386 \\
\hline \multicolumn{4}{|c|}{ Household covered by health insurance [No as reference $]$} \\
\hline Yes & -.048 & .106 & .649 \\
\hline \multicolumn{4}{|c|}{ Wealth Index [Poorest as reference] } \\
\hline Poorer & -.005 & .064 & .935 \\
\hline Middle & .122 & .066 & $.062^{* *}$ \\
\hline Richer & .351 & .075 & $.000^{*}$ \\
\hline
\end{tabular}




\begin{tabular}{|c|c|c|c|}
\hline Richest & .508 & .092 & $.000^{*}$ \\
\hline \multicolumn{4}{|c|}{ Place of residence [Capital and large city as reference] } \\
\hline Small City & -.410 & .100 & $.000^{*}$ \\
\hline Town & -.541 & .076 & $.000^{*}$ \\
\hline Countryside & -.485 & .069 & $.000^{*}$ \\
\hline $\mathrm{C}$ & 1.961 & .206 & $.000^{*}$ \\
\hline
\end{tabular}

Note: *represents 5 percent and $* *$ represents 10 percent level of significance.

Out of sixteen variables, ten have been emerged as significant determinants of TT vaccination of Indian women. They are woman's age at first marriage, woman's education, birthorder of child, husband's age, husband's education, husband's living in the home, husband's presence during prenatal visit, final say on woman's health-care, wealth index and place of residence. The woman's working status, ever terminated pregnancy, husband's working status, gender of head of household, family structure (nuclear or combined) and household covered by health insurance have shown no significant effect on the likelihood of TT vaccination.

\section{DISCUSSION}

The analysis in the current study helps us to identify the socioeconomic determinants of TT vaccination. In the individual characteristics, the woman's age at first marriage negatively affects the likelihood of TT vaccination. Age is an important determinant of female health-seeking behavior in social perspectives. Woman's education is also an important determinant of healthseeking behavior. In our results education of the woman as a categorical variable has positively influenced the likelihood of TT vaccination.

All the categories of woman's education, i.e.primary, secondary and higher enhance the probability of TT vaccination. The women with primary, secondary and higher level of education have 13, 12 and 48 percent likelihood to have TT vaccination as compared to those with no education. The higher level of education has shown the higher effect. The explanation may be that more educated women seek high quality prenatal-care and have greater ability to use health-care inputs to maintain their health (Beeckman et al., 2010; Titlay et al., 2010; Beeckman et al., 2011; Habibov, 2011). The education impacts individuals' behavior regarding health. It enhances the women' decision making power and confidence. The educated women may take preventive healthcare measures, as they have more control over their lives. They have positions in their households to take decisions regarding their own as well as children' health. Another explanation may be that education increases overall awareness including health and health-care utilization.

Birth-order of the child has shown significant result. It negatively affects the likelihood of TT vaccination. Such type of impact is supported by a number of studies. Women experiencing high number of births have less likelihood of maternal health-care (Titlay et al., 2010; Habibov, 2011). The possible explanation may be that during their earlier pregnancies females are more cautious and they attempt to seek maternal health-care. With the passage of time due to experience and confidence from previous pregnancies they feel less need of maternal health-care 
in the form of TT vaccination for subsequent pregnancies. Furthermore, at higher birth-order of child the women feel themselves secure due to TT vaccination during previous births.

In the household characteristics, our results have shown that husband's age increases the probability of TT vaccination. The husband's education has also been emerged as an important factor of TT vaccination of woman. All the categories of husband's education, i.e. primary, secondary and higher education enhance the likelihood of TT vaccination. Furthermore, by increase in level of education, the probability of vaccination rises more intensively.

Husband's living in the household is a socioeconomic and cultural variable representing the level of security and care to the wife particularly in South Asian perspective. If the husband is living in the family, it improves the household management in terms of child welfare and female care including wife, sisters and mother. In our data, the husband's non-living in the household may have the form that he is emigrant, working in another area within the country and outside the city, separated or bigamy. In all of these cases the wife feel empowered in decision-making and mobility. Our results have shown that if the husband is living in the household, it increases the probability of maternal health-care in the form of TT vaccination. From the results two important points may be inferred. Firstly the absence of husband in the household may not be symbol of women empowerment. If it is proxy of the empowerment, then empowerment of woman does not contribute in woman's health-care behavior. Secondly, the husband has a good role in household management. It explains that presence of husband in the household increases the welfare of the household. He makes good decisions regarding child welfare and female care. Due to presence of the husband in the household the woman may have easy access to the healthcare center. She feels comfortable in the presence of her husband at the center as well as during transportation and communication with the health-care providers. Our results have further shown that the presence of husband at the time of prenatal visit increases the probability of TT vaccination. Both the results corroborate each other. It may be proposed that the husband should take attention in the case of woman when she is expecting a child. For the purpose, the cultural norms in India and generally in South Asia need transformation. The husbands feel slightly ashamed in accompanying the wives during their prenatal visits. It is linked with lack of awareness and information about advantages of prenatal-care. The results may be linked to the result of age of the husband and his education.

In our analysis the final say on the decision of maternal health-care has three categories, whether the final say is of woman, woman and her husband or husband alone. The variable represents the woman's empowerment.

Our results have shown that the final say of the woman and husband (collectively) and husband alone slides down the likelihood of maternal health-care in the form of TT vaccination. The result is corroborated with the earlier discussed variable of living of husband in the household. From result of that variable we have inferred that absence of the husband from the household is not a good proxy of woman autonomy. The results of current variable, i.e. final say on the decision of the maternal health-care also supports the notion that absence of husband from household is not a good proxy of the woman's autonomy particularly explaining maternal health- 
care. Enhancing the woman's empowerment through participation in decision-making about her health may be a good instrument to increase the maternal health in India.

Wealth index expresses the socioeconomic status of the household. IDHS has developed household wealth index from several household characteristics and asset variables using a principle component analysis. It has been divided into quintiles from lowest to highest. These quintiles have been included in the analysis. Our estimates have shown that probability of TT vaccination increases with higher quintiles ${ }^{7}$. It explains that household wealth is a key determinant of maternal health-care in the form of TT vaccination. Poverty reduction and to enhance the socioeconomic status of the people is a long-term strategy pursued by the governments of developing economies like India. The immediate and short-term solutions are needed to mitigate the negative effects of poverty on maternal health-care in the form of TT vaccination. The international experience demonstrated that one of the ways to target with limited resources to the poorest women is through cash conditional social assistance programs. For instance, the Oportunidades in Mexico and Program for Advancement through Health and Education (PATH) in Jamaica use various types of targeting techniques to identify the needy households and provide them the social transfer, conditional on school attendance and health-care checkups. Similar is the case of FEMME in Peru for reducing maternal death rate, and Keluarga Harapan and Program Nasional Pemberdyyaan Masyarakat-Generasi Sehatdan Cerdas in Indonesia for reducing maternal mortality, and covering basic education. In Guatemala MiFamilia Progresais the program for families living in poverty and extreme poverty and for pregnant women or necessary mothers. In Columbia and Panama, there are success stories of linking health benefits with social assistance programs. National Rural Health Mission (India) has a mandate to make quality health-care accessible to all, particularly to the poor and the marginalized. Our results demonstrated that it is the poor and marginalized who are still out of the reach of government sponsored public health programs (see also, Singh et al. (2012). Government of India has also been promoting antenatal-care under the Reproductive and Child Health $(\mathrm{RCH})$ Program. It seemed ineffective to cover women of lower socioeconomic status households. Social assistance programs in India could be extended to cover eligible pregnant women and amount of benefits might be linked to TT vaccination. The Janani Suraksha Yojana program where women are paid cash incentive for delivering their babies in public health facilities or government-designed private facilities may contribute a lot for the purpose if it becomes effective by proper implementation.

Instead of using the rural-urban locality of the household as explanatory variable, we have included the large city/capital, small city, town and country side as categorical variables for locality of the household. The locality of the household has been emerged as one of the significant determinants of TT vaccination. The probability for TT vaccination decreases for the women living in small city, town and country side. The women living in small city have 41 percent less

\footnotetext{
${ }^{7}$ It contradicts the findings of Madico, G., G. Salazar., J. McDonald., W. Checkley., M. Calderon., M. Verastegui. and R. H. Gilman, 1996. where women of low socioeconomic class were having higher vaccination rates than their counterparts of high socioeconomic class. These women were, in fact targeted by vaccination programs, most of which were conducted by primary health-care providers for poor women.
} 
likelihood for TT vaccination as compared to the women living in large city/capital. Similarly the women residents of town and country side are 54 and 48 percent less likely to be TT vaccinated as compared to those of large city/capital respectively ${ }^{8}$. Such type of disparity is common characteristic of all the South Asian economies.

The explanation may be that there exists lack of health-care infrastructure in small cities, towns and country side. The transportation and traveling cost also matter for inhabitants of these localities. Moreover the incomes of such households are lower as compared to their urban counterparts. They are more inclined towards tradition and conventional tools to deal with health problems particularly of females due to social norms. On the other hand the households of large cities/capital have more access to education, information and awareness.

\section{CONCLUSION}

The empirical evidences emerged from this study have several implications for maternal health policy in India. Education of the women should be a part of the policy options. Along with an upsurge in maternal health-care a variety of spillover effects of women education may be obtained. The husband's characteristics like the age, education, presence in the household as well as presence while the wife visits for prenatal checkup enhance the probability of maternal healthcare in the form of TT vaccination. It may be concluded that husbands have significant role in maternal health-care in India. All the characteristics of the husbands are related with awareness, and information about prenatal-care. The institutional transformation is required to have the higher level of maternal health-care.

It may comprise of socio-cultural change focusing on maternal health and ultimately the infants health. In the public policy, the hospitals may give incentives to husbands for accompanying their wives for prenatal visits.

They may be free checkups of husbands along with wives during all visits. Supplement food for both husband and wife may be another option. Similarly, the child checkup after birth may be tied to the husband's presence during prenatal visits. However, the awareness, education and participation of husbands in prenatal-care cannot be ignored. The socioeconomic status proxied by wealth index has shown positive effect on likelihood of TT vaccination.

The wealth index is ultimately linked with household income. The subsidy and support programs for maternal-care may be a good choice for increasing the maternal health-care. The results demonstrated the existence of inequality in large cities/capital, small cities, towns and country side.

These inequalities explained the lack of regional priorities by government. The regional variables represent the supply side factors of maternal health-care. In the large cities the maternal

\footnotetext{
${ }^{8}$ It contradicts the results of Maral, et. al. (2001 for Turkey) where rural women are more likely to have TT vaccination as compared to urban ones. The explanation given was that urban doctors particularly involved in private hospitals do not consider TT vaccination absolutely necessary during pregnancy due to confidence and secure place of delivery.
} 
health-care services are available extensively as compared to the small cities and countryside. Public policy regarding provision of maternal health-care in small cities requires attention. As the residents of these localities have lower income so cost and prices be subsidized for these areas.

\section{REFERENCES}

Andersen, R. and J.F. Newman, 1973. Social and individual determinants of medical care utilization in the united states.Milbank memorial fund quarterly. Health Society, 51: 95-124.

Bassani, D.G., R. Kumar, S. Awasthi, S.K. Morris and V.K. Paul, 2010. Causes of neonatal and child mortality in india: A nationally representative mortality survey. The Lancet, 376(6755): 1853-1860.

Beeckman, K., F. Louckx and K. Putman, 2010. Determinants of number of antenatal visits in metropolitan region. BMC Public Health, 10: 527-535.

Beeckman, K., F. Louckx and K. Putman, 2011. Predisposing, enabling and pregnancy related determinants of late initiation of prenatal care. Maternal Child Health Journal, 15(7): 106-175.

Birch, S., M. Hass, E. Savage and G.K. Van, 2007. Targeting services to reduce social inequalities in utilization: An analysis of breast cancer screening in new south wales. Australian New Zealand Health Policy, 4: 12.

Black, R.E., D.H. Huber and G.T. Curlin, 1980. Reduction in neonatal tetanus by mass immunization of non-pregnant women: Duration of protectoin provided by one or two doses of alum-absorbe tetanus toxoid. Bulletin of World Health Organization, 58: 927-930.

Blecowe, H., J. Lawn, J. Vandelaer, M. Roper and S. Cousens, 2010. Tetanus toxoid immunization to reduce mortality from neonatal tetanus. International Journal of Epidemiology, 39: 102-109.

Gorossman, M., 1972. On the concept of health capital and demand for health. Journal of Political Economy, 82(2): 223-255.

Gupta, S.D. and P.M. Keyl, 1998. Effectiveness of prenatal tetanus toxoid immunization against neonatal tetanus in a rural area in india. Pediatric Infectious Disease Journal, 17: 316-332.

Habibov, N.N., 2011. On the socio economic determinants of antenatal care utilization in azerbaijan: Evidence and policy implications for reforms. Health Economics, Policy and Law, 6: 175-203.

Hasnain, S. and N.H. Shaikh, 2007. Causes of low tetanus toxoid vaccination coverage in pregnant women in lahore district. Pakistan. Eastern Mediterranean Health Journal, 13(5): 1142-1152.

Jordan, K., C. Jinks and P. Craft, 2006. A prospective study of the consulting behavior of older people with knee pain. British Journal of General Practice, 56: 269-276. 
Koeing, M.A., 1992. Mortality reduction from measles and tetanus immunization: A review of evidence. Child health priorities for the 1990s: Report of a seminar. Baltimore, m.D. June 20-22, 1991. The john hopkins school of public health institute for international programs, baltimore, 1992.

Lahariya, C., C.R. Sudfeld, D. Lahariya and S.S. Tomar, 2010. Causes of child deaths in india 1985-2008: A systematic review of literature. Indian Journal of Pediatrics, 77(11): 1303-1311.

Madico, G., G. Salazar., J. McDonald., W. Checkley., M. Calderon., M. Verastegui. and R. H. Gilman, 1996. Rates of tetanus protection and transplacented tetanus antibody transfer in pregnant women from different socioeconomic groups in peru. Clinincal and Diagnostic Laboratory Immunology, 3(6): 753-755.

Maral, I., Z. Baykan, F. Aksakal, N. , F. Kayikcioglu and M.A. Bumin, 2001. Tetanus immunization in pregnant women: Evaluation of maternal tetanus vaccination status and factors affecting rate of vaccination coverage. Public Health, 115: 359364.

Rahman, M., C. Chen, J. Chakraborty, M. Yunus, A.I. Chowdhury, A.M. Sarder, S. Bhatia and G.T. Curlin, 1982. Use of tentanus toxoid for the prevention of neonatal tetanus i. Reduction of neonatal mortality by immunization of non-pregnant and pregnant women in rural bangladesh. Bulletin of World Health Organization, 60: 261-267.

Redondo-Sendino, A., P. Guallar-Castilon, J.R. Benegas and F. Rodriguez-Artalego, 2006. Gender differences in the utilization of health-care services among the older adult population of spain. BMC Public Health, 6: 115.

Roosihermiatei, B., M. Nishiyama and K. Nakae, 2000. Factors associated with tt (tetanus toxoid) immunization among pregnant women in saparua, maluku, indonesia. South East Asian Journal of Tropical Medicine and Public Health, 31(1): 91-95.

Singh, A., S. Pallikachavasth, R. Ogollah and W. Stones, 2012. Maternal tetanus toxoid vaccination and neonatal mortality in rural north india. Plos One, 7: 11.

Stanfield, J.P. and A. Galazka, 1984. Neonatal tetanus in the world today. Bulletin of the World Health Organization, 62: 647-669.

Stanfield, J.P., D. Gall and P.M. Brecken, 1973. Single dose anti-tetanus immunization. Lancent, 1: 215-219.

Thind, A., 2005. Determinants of tetanus toxoid immunization in pregnancy in rural bihar. Tropical Doctor, 35(2): 75-77.

Titlay, C., R. Michal, J. Dibley and C.L. Roberts, 2010. Factors associated with underutilization of antenatal care services in indonesia: Results of indonesia demographic and health survey 2002/2003 and 2007. BMC Public Health, 10: 485-495. 
Whitman, C., L. Belgharbi, F. Casse, C. Torel, V. Mattei and F. Zoffmann, 1992. Progress towards the global elimination of neonatal tetanus. World Health Statistics Quarterly, 45: 248-256.

WHO, 1986. Prevention of neonatal tetanus through immunization who/epi/gen/86.9. Geneva: World Health Organization (WHO). 